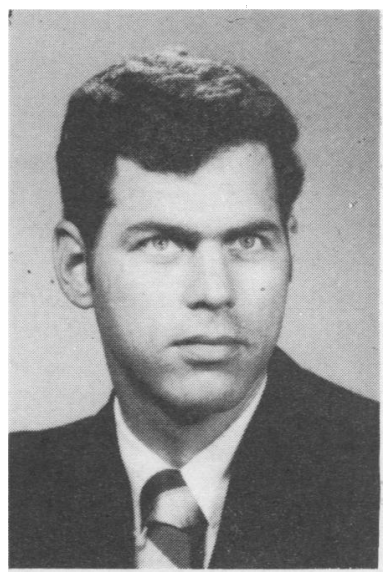

J. L. Mayhew

\section{AN INEXPENSIVE METHOD \\ OF DETERMINING BODY COMPOSITION BY UNDERWATER WEIGHING}

\author{
B. A. CLARK, PhDt and J. L. MAYHEW, PhD*
}

tHuman Performance Laboratory, Department of Behavioural Studies, University of Missouri - St. Louis, St. Louis, Missouri, USA

${ }^{*}$ Department of Physical Education, University of Illinois, Champaign, Illinois, USA

\author{
*Present address: \\ Human Performance Laboratory, \\ Physical Education Division, \\ Northeast Missouri State University, \\ Kirksville, \\ Missouri 63401, \\ USA
}

\title{
ABSTRACT
}

A simple, inexpensive densiometric method of determining body composition was compared to a more sophisticated one. Body density $\left(D_{b}\right)$, lean body mass (LBM), and relative fat content (\%fat) were determined for 16 volunteers, 9 men and 7 women using a simple T-bar apparatus suspended in a swimming pool, and an electronic apparatus in conjunction with a metal tank. Residual volumes (RV) used in the determinations were estimated from age and height (RV-1), held constant at $1,300 \mathrm{ml}$ for men and $1,000 \mathrm{ml}$ for women (RV-2), and measured by the nitrogen washout method (RV-3). No significant difference was observed between the two methods of weighing, although significant differences did exist among the RV techniques. It was concluded that a simplified method of determining body composition is acceptable for screening purposes, but long term studies might require more sophisticated techniques with RV measured at the time of weighing.

\section{INTRODUCTION}

The use of body composition measurements is an essential element of many physiological studies and classification systems used in general population screening. Primary among the parameters are body density $\left(D_{b}\right)$, lear body mass (LBM), and relative fat content (\%fat). The accepted criterion is hydrostatic weighing with pulmonary residual volume (RV) determined at the time of weighing (Buskirk, 1961). This, however, is an expensive procedure, due to the cost of the measurement devices used in determining RV. The prediction of LBM or \%fat from skinfold thicknesses has not proved successful in groups other than those for whom the equation was constructed (Katch and Michael, 1969;
Flint, et al, 1977).

A practical and inexpensive method for estimating $D_{b}$ and \%fat would be a benefit when screening relatively large numbers of people. However, the method would have to be of acceptable validity and be reliable.

This study compared an easily constructed, inexpensive " $\mathrm{T}$ " bar apparatus attached to a spring scale suspended from a projection above a swimming pool (e.g. a diving board), and a sophisticated underwater weighing apparatus using a submersion tank, sensitive transducers for weight determination and respiratory apparatus to estimate $\mathrm{RV}$. 


\section{METHOD}

Subjects. The subjects were 16 university physical education students, 9 men and 7 women, who volunteered for this study. The anthropometric characteristics of the two groups are shown in Table 1.

T-bar apparatus. The T-bar assembly consisted of two hollow copper rods: a short $(61 \mathrm{~cm})$ horizontal rod was used as a seat, attached to a long $(102 \mathrm{~cm})$ vertical rod via a welded copper sleeve. Height adjustment of the seat was accomplished by moving it to the appropriate height and securing it in places with a brass screw through adjusting holes located every $8 \mathrm{~cm}$. A $15 \mathrm{lb}$ weight provided subject-apparatus stability when submerged (Fig. 1). The T-bar assembly was attached to a Toledo $30 \mathrm{lb}$ triple revolution spring scale. The scale was suspended by a rope from the $1 \mathrm{~m}$ diving board of the swimming pool.

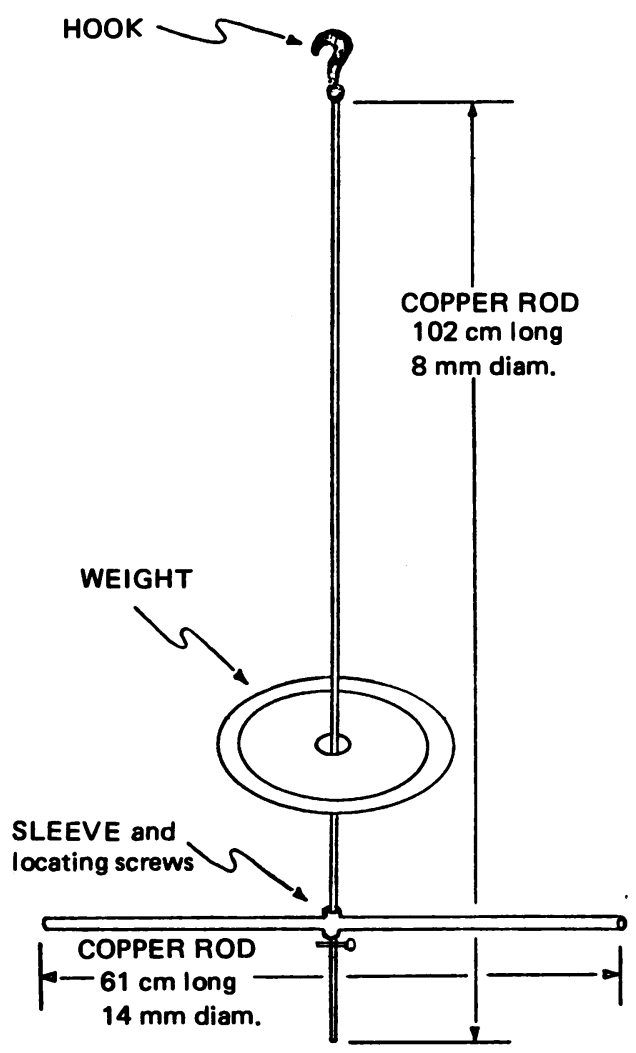

Fig. 1: T-Bar apparatus.

Tank apparatus. The subject was suspended underwater on a metal platform from two linear voltage differential transducers (LVDT) in a metal tank. The underwater weight was recorded on an ink recorder connected to a transducer amplifier (Daytronic, Model 300D).
Pulmonary RV was determined at the time of underwater weighing by the closed circuit nitrogen washout method of Wilmore (1969a).

Residual volume methods. Residual volume was determined in three different ways for comparing the methods of measuring $D_{b}$, LBM, and \%fat. In method one (RV-1), RV was estimated from body height (sex considered) using an adaptation from Baldwin, Cournand, and Richards (1948). In method two (RV-2), a constant of $1,300 \mathrm{ml}$ for men and $1,000 \mathrm{ml}$ for women was used (Wilmore, 1969b). In the third method (RV-3) RV was determined by the nitrogen washout method, using a nitrogen analyser (Med-Science, model 505).

RV and body density were calculated by each method of underwater weighing.

Underwater weighing technique. Initially, all subjects were made familiar with the T-bar technique in a practice session consisting of at least 10 trials (Katch, Michael and Horvath, 1967). On a second visit subjects reported to the experimental periods 12 hours postabsorptive. Wearing a swim suit, the subject positioned a rubber snorkel attached to the head by a rubber strap, applied a nose clip, and was seated on the T-bar. At least 10 trials were performed, with the mean of the final three recorded as the subject's underwater weight.

At a third session, the subject was measured in the tank method. Each subject was given four practice trials, followed by two actual measurements. After the submerged weight was recorded via the LVDT system, RV was measured by the nitrogen washout method. Residual volume was calculated from the formula of Cournand et al (1941). The mean of the two trials was used to calculate the body composition.

\section{RESULTS AND DISCUSSION}

The results of the calculations of $D_{b}, \%$ fat, and LBM using the two densiometric techniques are presented in Tables II and III, respectively. Two-way analysis of variance (ANOVA) for each variable revealed that while there was no significant difference between the two methods, significant differences among the RV techniques did exist. One-way ANOVA indicated that the three methods of estimating RV differed significantly. Residual volume was least when estimated from age and height (Baldwin et al, 1948) and greatest when measured by the nitrogen washout method (Wilmore, 1969a). Since body weights and underwater weights in the two methods differed by no more than $1.1 \%$, it must be assumed that the differences in $D_{b}, \%$ fat, and LBM are due to the methods of estimating RV.

The examination of the variations in RV within each subject supported the importance of the technique in 
TABLE I

Anthropometric Characteristics

\begin{tabular}{|c|c|c|c|c|c|c|c|}
\hline Subjects & $\begin{array}{l}\text { Age } \\
\text { (yr) }\end{array}$ & $\begin{array}{l}\text { Hoight } \\
\text { (cm) }\end{array}$ & $\begin{array}{c}\text { Woight } \\
\text { (kg) }\end{array}$ & $\begin{array}{l}\text { LBM } \\
\text { (kg) }\end{array}$ & $\begin{array}{l}\text { \%Fat } \\
\text { (\%) }\end{array}$ & 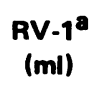 & $\begin{array}{c}\text { RV-2b } \\
(\mathrm{ml})\end{array}$ \\
\hline $\begin{array}{l}\text { Men } \\
(n=9)\end{array}$ & $\begin{array}{l}23.71^{d} \\
\pm 1.51\end{array}$ & $\begin{array}{r}180.5 \\
+5.7\end{array}$ & $\begin{array}{l}76.17 \\
\pm 7.98\end{array}$ & $\begin{array}{l}65.38^{e} \\
\pm 8.02\end{array}$ & $\begin{array}{l}14.1 \\
\pm 5.8\end{array}$ & $\begin{array}{r}1,054 \\
\pm 29\end{array}$ & $\begin{array}{r}1,300 \\
\pm 0\end{array}$ \\
\hline $\begin{array}{l}\text { Women } \\
(n=7)\end{array}$ & $\begin{array}{l}21.38 \\
\pm 2.02\end{array}$ & $\begin{array}{r}164.6 \\
\pm 5.0\end{array}$ & $\begin{array}{l}54.73 \\
\pm 4.63\end{array}$ & $\begin{array}{l}44.77 \\
\pm 3.65\end{array}$ & $\begin{array}{l}18.1 \\
\pm 3.7\end{array}$ & $\begin{array}{l}740 \\
\pm 22\end{array}$ & $\begin{array}{r}1,000 \\
\pm 0\end{array}$ \\
\hline $\begin{array}{l}\text { Composite } \\
(n=16)\end{array}$ & $\begin{array}{l}22.69 \\
\pm 2.53\end{array}$ & $\begin{array}{r}173.5 \\
+9.7\end{array}$ & $\begin{array}{r}66.79 \\
\pm 12.77\end{array}$ & $\begin{array}{r}56.36 \\
\pm 12.29\end{array}$ & $\begin{array}{l}15.9 \\
\pm 5.3\end{array}$ & $\begin{array}{r}914 \\
\pm 160\end{array}$ & $\begin{array}{r}1,169 \\
\pm 154\end{array}$ \\
\hline
\end{tabular}

TABLE II

Mean \pm SD, interrelationship of body density and \% fat using two densitometric methods

\section{Mothod}

1. $T$-bar RV-1 ${ }^{a}$

2. T-bar RV-2 ${ }^{b}$

3. T-bar RV-3

4. Tank RV-1

5. Tank RV-2

6. Tank RV-3

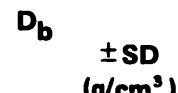

$\left(g / \mathrm{cm}^{3}\right)$

1.0468

1.0512

1.0549

1.0509

1.0554

1.0592

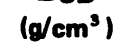

0.0137

0.0124

0.0137

0.0134

0.0131
0.0134

Mean
$(\%)$
22.4
20.6
19.1
20.7
18.9
17.3

$$
\pm \text { SD }
$$

(\%)

2

5.7

5.5

.99

5.1

5.6

5.5

5.3

TABLE III

Mean \pm SD, interrelationship of lean body mass using two densitometric methods

Mothod

1. T-bar RV-1 ${ }^{a}$

2. T-bar RV-2

3. T-bar RV-3c

4. Tank RV-1

5. Tank RV-2

6. Tank RV-3

\begin{tabular}{|c|c|}
\hline \multicolumn{2}{|c|}{ Lean Body Mass } \\
\hline $\begin{array}{l}\text { Mean } \\
(\mathbf{k g})\end{array}$ & $\begin{array}{c} \pm S D \\
(\mathbf{k g})\end{array}$ \\
\hline 52.40 & 12.17 \\
\hline 53.57 & 12.11 \\
\hline 54.65 & 12.32 \\
\hline 53.19 & 12.05 \\
\hline 54.35 & 11.99 \\
\hline 55.43 & 12.28 \\
\hline
\end{tabular}

2

.99

2.11

12.32

11.99

2.28

\section{3}

.99

.99
3

.94

.93

${ }^{a} R V$ estimated from age and height (Baldwin et al, 1948).

$b_{R V}$ was a constant $1,300 \mathrm{ml}$ for men and $1,000 \mathrm{ml}$ for women.

$c_{R V}$ measured by the nitrogen washout method (Wilmore, 1969a).

$\mathrm{d}_{\text {Mean }} \pm \mathrm{SD}$

${ }^{\text {O}}$ Measured using a tank method with RV measured at the time of underwater weighing. 
calculating $D_{b}$. The mean values for RV estimated with a constant and from age and height were 16.8 and $34.9 \%$ lower, respectively, than the nitrogen washout value (Table I). Errors as large as $21.5 \%$ in mean \%fat estimates could have resulted when an inappropriate RV was used in subjects that have either large RV's and/or inability to fully exhale while submerged. Other investigators have found that even in cases where RV is measured prior to immersion, significant variations in body composition measurements may occur (Sawka, 1974; Etheridge and Thomas, 1977). Greatest precision, therefore, is achieved when RV is measured at the time of underwater weighing.

Other studies have shown no difference in $D_{b}$ using various estimates of RV (Wilmore, 1969b; Sinning, 1974). In these studies, the mean actual RV was in close agreement with the assumed constant RV and an estimate of RV from vital capacity. This, related with the use of larger sample sizes, would lend support to the credibility of using alternative methods of estimating RV in calculating body composition for screening purposes. However, in one of these studies (Sinning, 1974), errors of $\pm 25 \%$ were possible in individual estimates of RV using prediction methods, which is comparable to the values found in the present study.

As Behnke and Wilmore (1974:24) have pointed out, when the effect of various exercise programmes on body composition is being assessed, an accurate measurement of RV appears critical. For screening purposes, however, the use of a simplified method of underwater weighing appears feasible. In addition, this method avoids the population specificity inherent in the prediction equations using skinfold, diameter, and/or circumference (Katch and Michael, 1969; Flint, et al, 1977).

Lean body mass was highly related no matter which RV estimate was used (Table III). These findings agree closely with other studies employing a simplified method of estimating RV (Sinning, 1974). Using the simple T-bar method, LBM can be estimated with an accuracy of $\pm 2.3 \%$. Therefore, a simplified underwater weighing apparatus employing an accurate autopsy spring scale and a constant RV is acceptable in screening studies. Where the body composition of subjects is to be followed accurately in long term studies, a more accurate measurement of RV should be made at the time of underwater weighing and this will require using more sophisticated techniques.

\section{REFERENCES}

Baldwin, E. De F., Cournand, A. and Richards, D. W., 1948 "Pulmonary insufficiency". Medicine 27: 243-278.

Behnke, A. R. and Wilmore, J. H., 1974 Evaluation and Regulation of Body Build and Composition. Englewood Cliffs, N.J.: Prentice-Hall.

Brozek, J., et al, 1963 "Densiometric analysis of body composition: revision of some quantitative assumptions". Ann.N.Y.Acad.Sci. 110: 113-140.

Buskirk, E. R., 1961 "Underwater weighing and body density: A review of procedures". In: Brozek, J. and Henschel, A. (Eds.) 1961. Technique for Measuring Body Composition. Washington, D.C.: National Academy of Sciences, National Research Council.

Cournand, A., et al, 1941 "Studies in intrapulmonary mixture of gases. IV The significance of the pulmonary emptying rate and a simplified open circuit measurement of residual air". J.Clin.Invest. 20: 681-689.

Etheridge, G. L. and Thomas, T. R., May, 1978 "The effect of body composition and water emersion on lung volumes of women". A paper presented to American College of Sports Medicine Meeting, Washington, D.C.

Flint, M. M., et al, 1977 "Validity of estimating body fat of females: effect of age and fitness". Human Biol. 49: 559-572.

Katch, F. I. and Michael, E. D., 1969 "Densiometric validation of six skinfold formulas to predict body density and percent fat of 17-year-old boys". Res.Quart. 40: 712-716.

Katch, F. I., Michael, E. D. and Horvath, S. M., 1967 "Estimation of body volume by underwater weighing: description of a simple method". J.Appl.Physiol. 23: 811-813.

Sawka, M. N., 1974 "A comparison of residual lung volume measurements on hydrostatic weighing specific gravity values in man". M. S. Thesis, East Stroudsburg State University, East Stroudsburg, PA. 
Sinning, W. E., 1974 "Body composition assessment of college wrestlers". Med.Sci.Sports 6: 139-145.

Wilmore, J. H., 1969a "A simplified method for determination of residual lung volumes". J.Appl.Physiol. 27: 96-100.

Wilmore, J. H., 1969b “The use of actual, predicted and constant residual volumes in the assessment of body composition by underwater weighing". Med.Sci.Sports 1: 87-90.

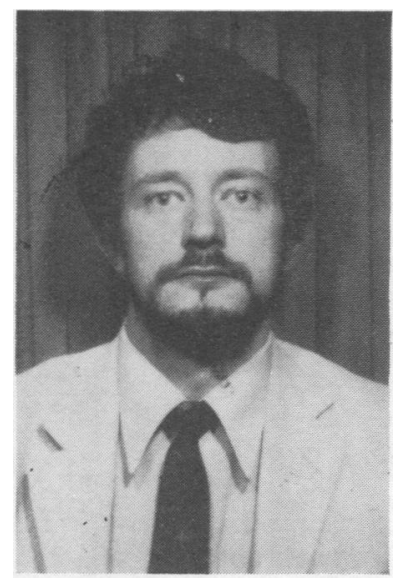

\title{
STROKE WHILE JOGGING
}

W. F. KELLY, BSc, MRCP* and J. ROUSSAK, BSc, FRCPt

*Manchester Royal Infirmary, Manchester M13 9WL

tUniversity Hospital, South Manchester

W. F. Kelly

\begin{abstract}
acute stroke sustained during jogging.

\section{CASE REPORT}

A 45-year-old male technical representative decided to commence jogging after publicity on television. He had stopped smoking eight years ago, but had taken no exercise since he stopped playing football at eighteen. He had suffered no serious illnesses, and blood pressure was normal in 1978 on routine examination. Both parents are alive and well, aged seventy-seven. He started jogging in cold weather in January, 1979. His first three runs were made at night and he was visibly exhausted on his return. He admitted to having pushed himself hard, as is his natural tendency. On the fourth night he collapsed while jogging alone. On examination, he was conscious but had receptive and expressive dysphasia. $\mathrm{He}$ was right-handed; tone and reflexes were increased
\end{abstract}

ABSTRACT

Jogging is a form of physical exercise that has stimulated the imagination of the public as shown by the recent appearance of its own journal (Jogging Magazine, Editor J. Bryant). We wish to report the unusual complication of an

on this side, with an extensor plantar response. There was no papilloedema or neck stiffness. The pulse was regular, 70 per minute, and the blood pressure was $110 / 75 \mathrm{~mm} \mathrm{Hg}$. His weight was $65 \mathrm{~kg}$ and height $175 \mathrm{~cm}$. Chest and skull $x$-rays were normal. A brain scan showed increased penetration of the isotope in the left parietal region. An arch aortogram showed normal aorta, carotid and vertebral arteries. A computerised tomography head scan showed a lesion in the left insula, clearly demonstrated when contrast medium was given intravenously, almost certainly an infarct (fig. 1). A left carotid angiogram was normal. Other results were: ECG normal on two occasions, cardiac enzymes not elevated; $\mathrm{Hb}$. $14.8 \mathrm{~g} / \mathrm{dl}$, white blood count, differential and platelets normal, plasma viscosity and blood clotting factors normal, ESR 15 (later 6) mms/hour, cryoglobulins and 